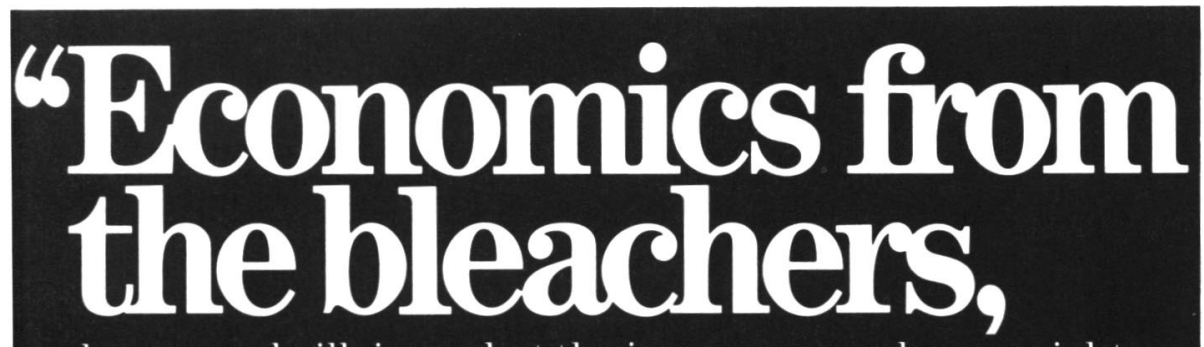

heroes and villains, what the issues were, who was right, and why supply-side economics was a hoax-economic journalism as lively and informed as it comes."

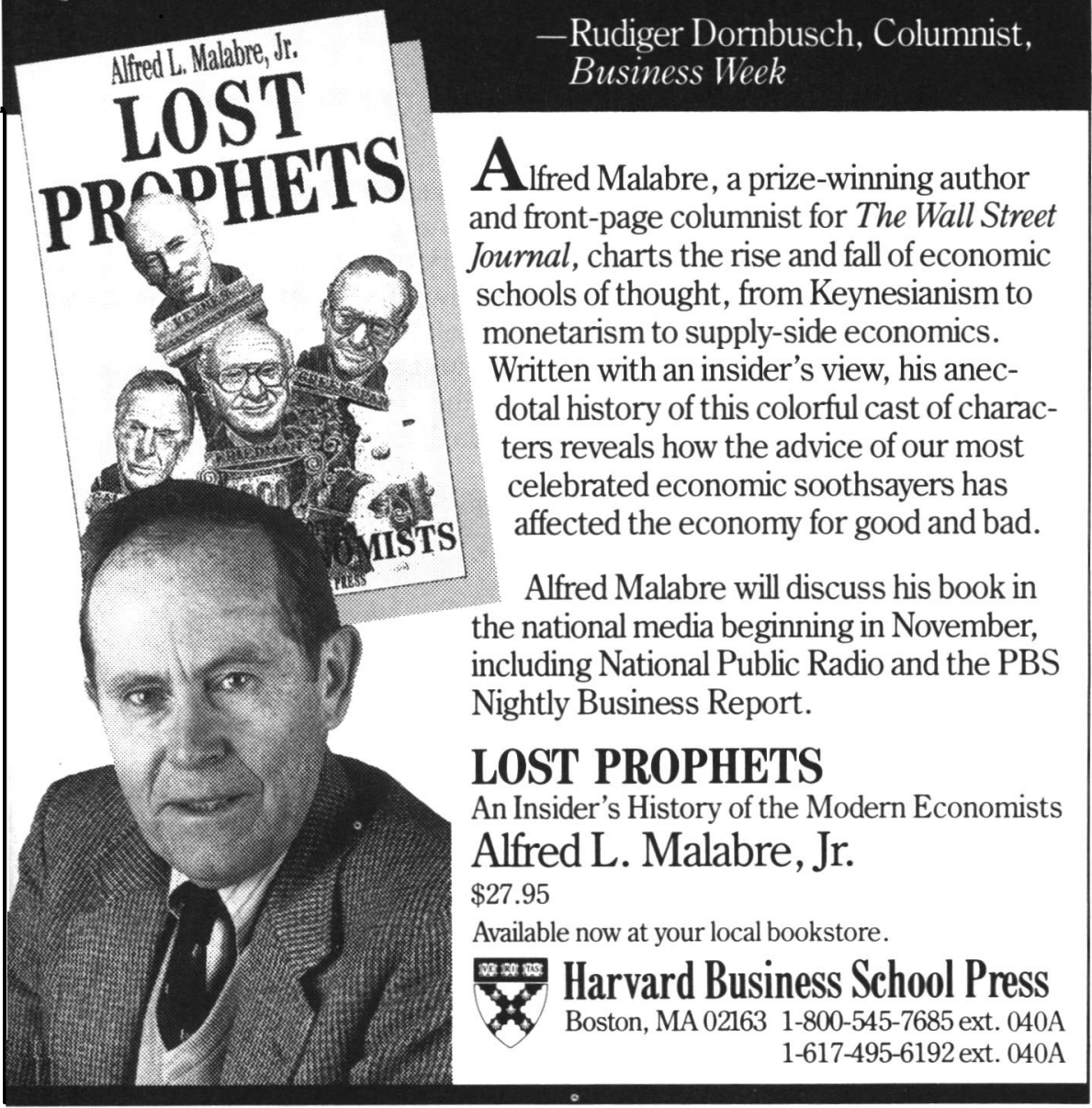




\section{UNEASY PARTNERS}

BIG BUSINESS IN AMERICAN POLITICS, 1945-1990

\section{Kim McQuaid}

"Businessmen are politicians in America," writes Kim McQuaid, "and politicians arebusinessmen." Today, in areas as diverse as home mortgages, high technology, and Smart Bombs, the private and public sectors are working together to perform tasks that each is unable to do alone. In Uneasy Partners McQuaid surveys the close ties that have formed between big business and government in the period from World War II to the present.

The American Moment: Stanley I. Kutler, Series Editor

$\$ 12.95$ paperback

\section{ALTERNATIVE TRACKS}

THE CONSTITUTION OF AMERICAN INDUSTRIAL ORDER, 1865-1917

\section{Gerald Berk}

"Focusing on the important case of railroadization, Gerald Berk's first-rate study demystifies the origins of large-scale corporate organization in America. Berk connects insights from history of technology, law, political science, and organizational history to show, first, that there was a real 'regionalist' alternative in a leading sector of the 19th-century economy to large-scalenational corporate organization and, second, that this alternative was equally efficient. At a time when the reconstitution of American industrial order is on our country's agenda, Berk's exploration of the past is especially timely."

-Richard M. Valelly, Swarthmore College

The Johns Hopkins Series in Constitutional Thought: Sotirios A. Barber and Jeffrey $K$. Tulis, Series Editors $\$ 35.95$ hardcover

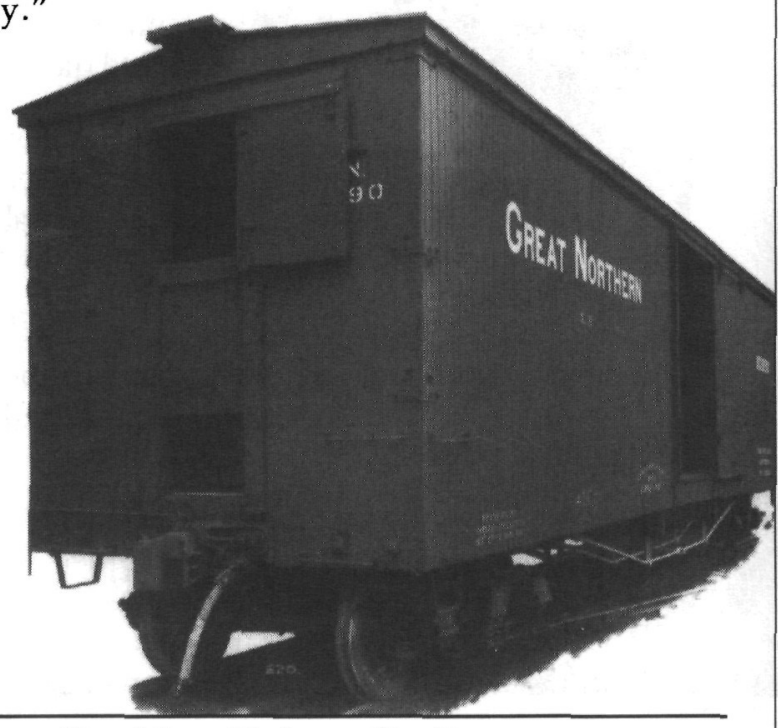

The Johns Hopkins University Press Hampden Station, Baltimore, Maryland 21211

To order, call 1-800-537-5487. 


\section{GUIDELINES FOR CONTRIBUTORS}

\section{General Information}

Manuscripts are considered for publication on the understanding that they are not concurrently under consideration elsewhere and that the material-in substance as well as form-has not been previously published.

Three copies of the manuscript should he submitted.

Authors should identify themselves only on a separate title page that provides name, mailing address, and telephone number. Authors must also remember not to identify themselves in the body of the manuscript; specitically, references to their own work in the text should be in the third person, and citations should be written without possessive pronouns-not "See my. . . ."

Each article should be accompanied by a précis of 75-100 words outlining the main point(s) of the paper and placing the article in context. Subheads should be used to divide the manuscript into three or four sections (or more, depending on length).

We do not have an upper or lower page limit, but articles usually nu between 25 and 60 typescript pages, including notes and other material.

Articles must contain notes in the humanities style, not references as in the social sciences.

We are always eager to publish illustrations, but authors should not include originals of illustrative materials at the time of subnission; photocopies of such material may be included.

Authors of accepted manuscripts will receive two copies of the issue in which the article appears and twenty-five free offprints.

\section{Manuscript Preparation}

ALL material-including extracted quotations and notes-must be ctouble-spaced. Legible photocopies or word-processed originals may be submitted. Use of dot-matrix printers is discouraged.

Notes should be numbered consecutively and citations should be placed at the end of the text. Do not place footnotes at the bottom of the page (sec word-processing instructions).

Each table or figure should occupy a separate page and should be numbered (in arabic numerals) and grouped together between the text and the notes. The position of these items should be indicated in the text (as, "see Table 3 "), but they should not be mingled with the text and no extra space should be left for them there. Each table and figure must be accompanied by a complete source.

We use the 13th edition of The Chicago Manual of Style (1982) and spell and hyphenate words according to Webster's Ninth Now Collegiate Dictionair.

The journal encourages authors to use gender-neutral prose in all cases where it is not anachronistic to do so; male nouns and pronouns should not be used to refer to people of both sexes.

We use the day-month-year form for dates, as 11 February 1990

Double quotation marks should be used for journal titles and direct quotation; single quotation marks are used for quoted material inside quotations.

Sample Citation Forms:

Book: Altred D. Chandiler, Jr., The Visible Hand: The Managerial Revolution in American Business (Cambridge, Mass., 1977), 321-22.

Journal: Charles Cheape, "Not Politicians but Sound Businessmen: Norton Company and the Third Reich," Business History Roviow 62 (Aurumn 1988): 444-66.

Note that we do not include the publisher in book citations. We do not use loc. cit. op. cit., or idem., but ibici. (not italicized) may be used.

\section{Wond-Processing Guidelines}

The journal can accept disks of all standard sizes and densities, but they must be formatted in MS-DOS; we cannot use Apple or Macintosh software. WordPerfect is directly compatible, but we may be able to accept your document it it can be converted into an ASCII file.

Potential contributors should submit hard copy, not diskettes, initially, but it will save considerable work for all partics in the event of acceptance if authors working on PCs follow a few rules from the beginning:

In general, use as fow formatting commands as possible.

Do not justify or half-justify the right-hand margin.

Do not hyphenate words at the end of lines.

Do not use hard returns except for new paragraphs or required page ends except as absolutely necessary (for example, to break between text and notes).

Do not use special fonts; underline material that is to be set in italics.

Most important, do not use the word processor's automatic footnote functions: do not embed notes in the text. Notes should be keyed in at the end of the text (after any tables) or as a separate file. 


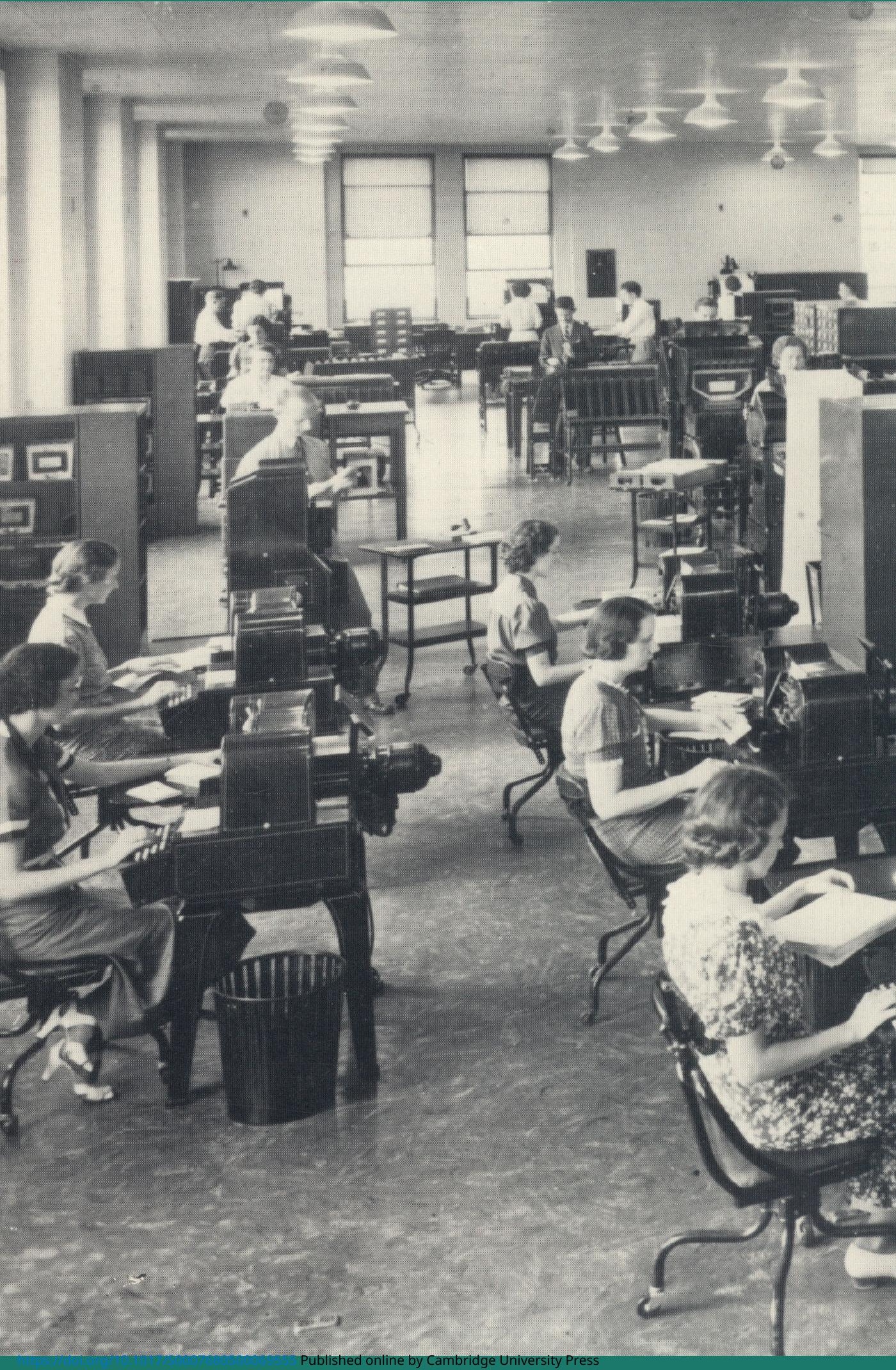

